\title{
Awareness about plagiarism and the effectiveness of library literacy program towards its deterrence: A perspective of postgraduate resident doctors
}

\begin{abstract}
Purposes- Awareness about plagiarism is essential for the evasion of intellectual mendacity, inculcation of academic integrity and assurance of quality research. Maintaining high standards regarding academic integrity is a major challenge for higher education and research organizations. In Pakistan, resident doctors are required to submit a dissertation to the College of Physicians and Surgeons. The purpose of this study is to examine this cohort's awareness of plagiarism and to determine the effectiveness of library information literacy (IL) program in the prevention of plagiarism.
\end{abstract}

Design/methodology/approach- Using the quantitative approach, a cross-sectional survey method was used. A convenience sample of postgraduate resident doctors was randomly recruited from two well-regarded hospitals in Peshawar, Pakistan. Data was collected through questionnaires. Descriptive and inferential statistics were utilized for data analyses.

Findings- The findings revealed that while resident doctors were aware of the concept of plagiarism, there were variations in their definition of the term. That said, they perceived plagiarism as an unethical practice and supported the implementation of anti-plagiarism policies. However, the respondents' knowledge was not strong regarding citation styles, specific anti-plagiarism policies, and plagiarism penalties. Likewise, this cohort was unfamiliar with library IL activities and their role in the prevention of plagiarism. Lastly, collaboration was absent among key stakeholders, e.g. resident doctors, research supervisors and librarians, to deter plagiarism.

Implications/limitation- This study recommends collaboration among the key stakeholders to ensure the delivery of consistent messages and to reinforce the importance of plagiarism prevention. Since this study was limited to two hospitals, similar research could be undertaken using a larger sample of resident doctors. It would also be useful to survey the librarians providing support for this cohort.

Originality/value- This study is the first attempt to examine the effectiveness of hospital library IL programs in the prevention of plagiarism among resident doctors in Pakistan. The findings are applicable to other health libraries worldwide that wish to address the challenge of plagiarism among health researchers in general.

Keywords: Plagiarism, Research policies, Health libraries, Information literacy, Research ethics, Intellectual integrity 


\section{Introduction}

Maintaining quality and standards within higher education and research organizations is a complex challenge. This is particularly true of academic integrity, which the International Centre for Academic Integrity defines as a commitment to six fundamental values: honesty, trust, fairness, respect, responsibility, and courage (Fishman, 2014). Preventing misconduct assists these organizations to assure their academic and research reputation, ensure that students receive appropriate credit for the work which they submit for assessment, and meet any reporting and compliance obligations. Importantly, academic integrity underpins a responsible research culture.

One specific aspect of academic integrity which has received a great deal of attention for a number of decades is plagiarism. For example, Aswathi (2019), in her systematic review, identified 408 studies on plagiarism and academic misconduct during 2009-2018 which met her criteria that the publication not only cover reasons for and types of plagiarism but also suggest avoidance strategies. Research shows that discussions about plagiarism are made more complex by factors such as the plethora of definitions for the term (Helgesson and Eriksson, 2015; Aswathi, 2019) and the variance among world cultures in addressing the issue (Handa and Power, 2005; Maxel, 2013; Hu and Sun, 2017; Ison, 2018).

While much of the research on student plagiarism tends to focus on the rate of incidence and the motivations for it (Childers and Bruton, 2016), it is also useful to study the degree of awareness among designated cohorts. This is particularly applicable when examining those countries in which plagiarism constitutes a significant challenge. Universities in countries such as Bangladesh, Iran, and Pakistan, for example, have been reported as not possessing specific policies on academic integrity, while exhibiting a lenient approach to plagiarism (Ison, 2018).

Within Pakistan, several health organizations are, in fact, striving to address the problem. The College of Physicians and Surgeons Pakistan (CPSP), for example, is promoting quality research by implementing anti-plagiarism policies (https://www.cpsp.edu.pk/fcps.php). This is important because resident doctors in Pakistan are required to Initially submit a research proposal, followed later by a dissertation, to the Research Evaluation Unit (REU) of CPSP (https://www.cpsp.edu.pk/reu.php). However, recent research has shown that studies regarding the perception of plagiarism, its awareness, and prevention policies among Pakistani medical faculty members and students are limited (Rathore et al., 2015).

Therefore, as suggested by Michalak et al. (2018), the author(s) of this study perceived this gap as an opportunity to investigate potential collaboration between librarians and relevant stakeholders. Given the documented contribution in the literature of library 
information literacy (IL) programs toward the prevention of plagiarism, the intended study was undertaken in the context of postgraduate resident doctors enrolled in two wellregarded teaching hospitals in Peshawar, Pakistan. Initially, this study explored how resident doctors perceive and understand the definition of plagiarism as well as how much they know about the plagiarism prevention policies formulated and implemented by CPSP throughout the country for health researchers. Finally, it examined this cohort's awareness of the role of library IL programs in the prevention of plagiarism.

With this in mind, the study was guided by the following four research objectives:

1) To examine Pakistani resident doctors' awareness about plagiarism;

2) To determine how Pakistani resident doctors understand the definition of plagiarism;

3) To know Pakistani resident doctors' familiarity with anti-plagiarism policies;

4) To determine the effectiveness of library information literacy activities in the prevention of plagiarism

The results revealed that while, in general, the respondents were aware of plagiarism to varying degrees, they did not have enough knowledge of either appropriate prevention policies or strategies. As a result, implications exist not only for health libraries in Pakistan but also worldwide to improve collaboration between librarians and other stakeholders in order to have a more coordinated approach to addressing the issue of plagiarism.

\section{Literature Review}

Conceptualization of plagiarism- The introduction of the term plagiarism into the English language is generally regarded as dating from its use by Ben Johnson in the $17^{\text {th }}$ century (Vinod et al., 2011). While it is beyond the scope of this paper to examine the wide variation in meanings assigned both historically and currently to the term, research indicates that there are several key aspects which need to be considered in any discussion of the topic. First, there is, in fact, quite a variance in how plagiarism is defined, depending upon the level of specificity for a particular circumstance. It may be as broad as "textual borrowing" (Pennycook, 1996, p. 202) and "steal[ing] passages" (Sharkey and Culp, 2005, p. 114) or defined in terms of specific categories such as conceptual, intentional, and unintentional (Cheema et al., 2011; Ramzan et al. (2012)). Second, people from different socio-cultural backgrounds may perceive plagiarism differently (Handa and Power, 2005; Gunnarsson et al., 2014). Likewise, Duff et al. (2006) have stated that understanding the concept of plagiarism is contingent on an individual's educational, social, historical and cultural assumptions. Third, an understanding of plagiarism is also dependent upon "complex relationships between text, memory, and learning" (Pennycook, 1996, p. 201). Based on the above discussion, it is deduced that organizations and researchers have defined the term plagiarism in their context. Since this study was undertaken in terms of 
resident doctors of Pakistan, thus for conceptual clarity the definition provided by CPSP was adopted for this study. According to this definition, plagiarism is an act of getting or trying to get credit for intellectual works through rephrasing, copying, summarizing, changing words, transforming figures into data and vice versa or data manipulation produced by researchers without accurate acknowledgement or accurate citation (https://www.cpsp.edu.pk/hcsm-policies-and-procedures.php.

Prevalence of plagiarism- The incidence of plagiarism among students, faculty, and researchers has been well documented for the past five decades. Although included as part of the larger issue of academic misconduct, Bower's first large-scale study in 1964 of American college students found that seventy-five per cent had engaged in some form of "cheating" (Owunwanne et al., 2010). Similarly, Gilmore et al. (2010) revealed that, in a study of research proposals submitted by graduate students at three American universities, forty per cent contained notable plagiarism. In the same year, East (2010) cited large scale American studies showing evidence of over seventy per cent of students have admitted to some form of academic cheating, including plagiarism. Studies in other countries have also identified plagiarism as a major challenge (Hosny and Fatima, 2014; Singh and Guram, 2014; Foltýnek and Glendinning, 2015; Singh, 2017; Mohamed et al., 2018). Hodges et al. (2017) have theorized that plagiarism among doctors in Arab and Asian countries is growing and needs prevention. Additionally, easy access to digital resources has been identified as a major contributing factor to researchers' use of plagiarism (Mirza and Staples, 2010). In the context of Indian health professionals, Singh and Guram (2014) posited that ignoring plagiarism augment intellectual dishonesty and its prevalence. The prevalence of plagiarism which is also known as incidences of academic dishonesty and cheating is not new and trace back to the industrial revolutions (Abukari, 2016). In 2007, the Higher Education Commission (HEC) of Pakistan implemented antiplagiarism policies in Pakistan (https://www.hec.gov.pk/english/services/faculty/Plagiarism/Pages/default.aspx).

However, Ramzan et al. (2012) have posited that twenty-four per cent of Pakistani graduate and postgraduate students in twelve randomly selected universities were involved in plagiarism in 2010. Additionally, a recent survey by Javaeed et al. (2019) reported a range from fifty-seven to sixty-five per cent use of plagiarism among a select postgraduate cohort in two Pakistani provinces, despite the HEC policies. Besides, in the context of students and researchers, different types of indicators have been linked with the prevalence of plagiarism. For instance, Harper (2006) validated demographics, academics, social, technological and environmental conditions as the predictors of incidences of plagiarism. Besides other causes that augment the prevalence of plagiarism include the absence of penalty, teaching and learning styles, and failure to adequately use citation styles (Tran et al., 2018). 
Plagiarism in medical science- Given the research objectives of this study, the researchers were particularly interested in this specific aspect of plagiarism. The term plagiarism was first introduced by PubMed as a medical subject heading (MeSH) in 1990 and was defined as "passing off as one's own the work of another without credit" (Khemiss et al., 2018, p. 66). Research over time continues to demonstrate that plagiarism is a challenge for medical researchers and particularly medical students (Rennie and Crosby, 2001; Elzubeir and Rizk, 2003; Bilic-Zulle et al., 2005; Derby 2008; Abdullah, 2014; Singh and Guram 2014; Ismail, 2018; Mohamed et al., 2018). Recent studies show that plagiarism continues to be a serious ethical issue for Pakistani medical researchers. Shirazi et al. (2010) reported a high level of lack of knowledge among Karachi medical faculty and $4^{\text {th }}$ year medical students. In a survey of seven Pakistani medical colleges, Rathore et al. (2015) found that approximately seventy-six per cent of faculty and eighty per cent of students believed that they worked in an environment characterized by plagiarism. According to Javaeed et al. (2019), plagiarism is still a common practice among postgraduate medical students in Pakistan.

Knowing that plagiarism has become a sturdy challenge for academia, multiple health organizations in Pakistan are striving for its deterrence. For example, the College of Physicians and Surgeons (CPSP) is steadfast to promote quality research by implementing anti-plagiarism policies in Pakistan (https://www.cpsp.edu.pk/fcps.php). To strengthen the research skills of postgraduate resident doctors, CPSP has organized multiple training sessions. To complete their training, the Pakistani resident doctors are required to submit research proposals and then dissertations to the Research Evaluation Unit (REU) of CPSP (https://www.cpsp.edu.pk/reu.php). The REU is responsible to provide online resources explaining the format and writing styles of research proposal and dissertation. It safeguards research protocols, appraisal of proposals, dissertations and prevents plagiarism through executing prevention policies. However, Rathore et al. (2015) suggested that CPSP can take strict actions against plagiarist. Even though CPSP has indicated zero-tolerance policy for plagiarism and clarified its penalties as expulsion from program or disqualification, still less than $20 \%$ similarity index is acceptable (https://www.cpsp.edu.pk/hcsmpolicies-and-procedures.php).

Motivators of plagiarism- Although the researchers did not specifically assess respondents' perceptions of potential motivators to conduct plagiarism, the former found that a number of studies were particularly useful because of their implications for prevention strategies. For example, several studies posited that leniency and/or lack of punishment of plagiarists could act as an incentive for researchers to engage in plagiarism (Ramzan et al., 2012; Gullifer and Tyson, 2014). Postle (2009) highlighted instances in which researchers reported that their supervisors ignored plagiarism. In the survey undertaken by Ramzan et al. (2012) in Pakistan, forty-five per cent of the respondents claimed that their institutions did not possess plagiarism detection systems. The past 
researchers have reported different factors that motivated plagiarism. For example, Pamies et al., (2020) validated the lack of knowledge as a motivator of plagiarism. Similarly, Nazir and Aslam (2010) recognised poor learning experiences, illiteracy and unfamiliarity with plagiarism as motivators. Further, Chen and Chou (2017) designated low learning interest as the cause of plagiarism. Researchers' poor writing skills were also recognized as a major cause of plagiarism (Pecorari and Petric, 2014). Likewise, in the research findings, the desire to achieve better grades is validated predictor of plagiarism (Akbulut et al., 2008). According to Ramzan et al. (2012), social pressure is the strongest motivator of plagiarism among Pakistani students. Their findings elaborated that authorities are not addressing plagiarism adequately, and thus plagiarists go unpunished, undetected and thereby motivate others to engage in plagiarism. Additionally, leniency in the implementation of anti-plagiarism policies has also stimulated researchers towards plagiarism (Gullifer and Tyson, 2014). In terms of health research, Rathore et al. (2015) revealed that what motivates plagiarism among the doctors is still unknown.

Role of anti-plagiarism policies- As mentioned previously, Ison (2018) has noted that universities in countries such as Bangladesh, Iran, and Pakistan have been reported as not possessing specific policies on academic integrity. It is perhaps the major work done by Foltýnek and Glendinning (2015) that best clarifies why this is a critical omission for higher education institutions concerned about assuring their academic and research reputation. Devlin and Gray (2007) have suggested training/seminars on anti-plagiarism policies. Furthermore, Maxel (2013) has recommended the provision and strict implementation of anti-plagiarism policies among doctors to protect original authorship. Additionally, Pecorari and Petric (2014) have suggested that plagiarism policies must direct supervisors and librarians to organize seminars on referencing styles. According to Anney and Mosha (2015), prevention policies must direct researchers to promote intellectual integrity and strive for deterrence of plagiarism in the interest of quality research.

The College of Physicians and Surgeons Pakistan (CPSP), which was briefly mentioned above, is the national authority responsible for the deterrence of plagiarism among medical researchers through the implementation of its policies. The antiplagiarism policies (https://www.cpsp.edu.pk/hcsm-policies-and-procedures.php) briefly explain; 1 ) it has zero tolerance on plagiarism to enhance intellectual integrity, 2) defined plagiarism for the medical professionals and students to deter its occurrence and create awareness, 3) direct the supervisors, program coordinators and other authorities to familiarize medical students and doctors with the concept of plagiarism and its consequences on their work, 4) plagiarism is detected through Turnitin software, 5) maximum acceptable similarity index is $19 \%$, and students must submit their research with similarity index report and 6) all the supervisors are directed to train medical students about the use of CPSP anti-plagiarism policies. Given the relatively high incidence of 
plagiarism in medical science despite the formulation of a national policy, Javaeed et al. (2019) have recommended the formation of a plagiarism evaluation committee to monitor and ensure intellectual integrity.

Plagiarism prevention- As a complement to anti-plagiarism policy, research studies have either reported on prevention strategies or suggested areas for improvement. For example, several researchers (Batane, 2010; Javaeed et al., 2019) have recommended the adoption of detection software, such as Turnitin, to detect plagiarism. Others have pointed to the lack of enforcement of any formal anti-plagiarism policy which may already exist within an organization, thus rendering the policy ineffectual (Rathore et al., 2015; Javaeed et al., 2019; Khemiss et al., 2019). It is, therefore, logical to examine the role that the library can specifically play as a key stakeholder in tackling plagiarism.

Information literacy and plagiarism- Given their focus on supporting learning, teaching, and research, it is unsurprising that librarians already have a documented role in plagiarism prevention. According to Fister (1992), US librarians have collaborated since the 1980 s with faculty to teach information literacy skills to students, of which plagiarism is an important component. In a national US survey with 610 respondents, Gibson and Chester-Fangman (2010) found that 87 per cent of librarians felt they had a role in teaching plagiarism prevention. In 2016, Strittmater and Bratton identified a number of universities in which "librarians collaborate with faculty and staff from academic support centres to develop a broadly disseminated plagiarism prevention curriculum" (p. 9). Recent research has reinforced the key role in other countries, such as Australia and Canada, of the library in this domain (Bell, 2018; Burger, 2018; Idiegbeyan-Ose et al., 2019; O'Donnell et al., 2020).

According to Ramzan et al. (2012), in Pakistan anti-plagiarism policies have never been an integral part of the curriculum within universities. Moreover, the teaching about, and prevention of, plagiarism are not necessarily elements of every library's IL program and thus Pakistani researchers are unaware of the contribution of IL toward the prevention of plagiarism. Therefore, the authors have recommended that not only should IL be an integral support activity within libraries, but also librarians can use it as a strategy for the prevention of plagiarism. In addition, Soroya et al. (2017) have encouraged librarians in Pakistan to promote the HEC's mandatory anti-plagiarism policies as a foundation for academic integrity.

Regarding medical science, Ayre et al. (2014) have reported measurable benefits from the provision of information skills training within the National Health Service (NHS) England. In Canada, McClurg et al. (2015) have recommended that librarians and medical faculty seek opportunities to work together to formally include the library into the undergraduate medical education at the University of Calgary. Echoing this sentiment, Ullah and Ameen (2014) have reported on the poor IL skills of Pakistani doctors and have 
concluded: "There is a need [for medical librarians] to develop educational partnerships with faculty to integrate IL instruction into the mainstream curriculum, to teach it at a more in-depth level, and to provide better assessment" (p. 287). They attribute the need for the library to take actions because information literacy has yet to be included in the curriculum of all of the library and information science (LIS) schools in Pakistan.

The literature review has highlighted that, while plagiarism may be generally viewed among higher education and research organizations as an unethical practice, it is a complex issue to address. Within Pakistan, the nexus between medical education and low levels of knowledge about important aspects of plagiarism, particularly prevention, is concerning. Therefore, this study is an attempt to investigate an as yet unstudied cohortpostgraduate resident doctors-and their perceptions of the effectiveness of library information literacy (IL) programs in the prevention of plagiarism.

\section{Methodology}

Design of the study- adopting a quantitative approach and cross-sectional survey method this descriptive research was carried out from January 2020 to April 2020. A foursection questionnaire was administered to a sample of postgraduate resident doctors in Peshawar, Pakistan. Survey method was adopted because it has a maximum response rate, is cost-effective, easy and convenient (Kumar et al., 2013), suitable for the study of attitude, behaviour, and opinion about any practices (Creswell and Zhang, 2008). Based on inclusion and exclusion criteria, this study assured that study participants are undertaking research on approved topics and will submit their dissertation to the CPSP.

Population and sampling techniques- This study was undertaken in two highly regarded teaching hospitals in Peshawar, Pakistan: Hayatabad Medical Complex (HMC) and Khyber Teaching Hospital (KTH). These two hospitals were selected because of high enrollments for specialization, diversity in speciality departments, large facilities including well-stocked libraries, highly preferred for specialization. Due to the unavailability of a list of resident doctors (population frame), convenience sampling was found appropriate and adopted. Using personal contacts and frequent visits to these two hospitals a partial list of residents was prepared. Finally, a total of 916 residents were randomly recruited from different speciality departments as a sample of this study.

Development of measurement instrument- guided by a critical review of related literature on plagiarism, IL and further consultation with experts, a data collection instrument was designed. As provided in the Appendix, the survey was consisted of thirtythree items divided into five sections namely; 1 ) demographic profile of respondents was consisted of four items, 2) awareness about plagiarism was measured through eight items, 3) to measure how doctors understand plagiarism, a number of definitions with different descriptors and classifiers were provided (seven items), 4) knowledge of anti-plagiarism 
policies was evaluated through six items and, 5) effectiveness of library IL program was assessed by eight items. Excluding the demographics, all items were measured through a five-point Likert scale anchored as 1-strongly disagree and 5-strongly agree. For content and face validity, the selected expert panel was consisted of three medical researchers and two health librarians. These medical researchers had the experience of research supervision and knowledge of plagiarism including its detection strategies and prevention policies. Further, librarians in the panel have also organized IL activities for doctors and had familiarity with anti-plagiarism policies. Suggestions from the expert panel were thoroughly incorporated in the final version of the survey instrument. After validation, the questionnaire was pilot tested and yielded an acceptable minimum reliability value of 7.8 (Sekaran and Bougie, 2019). As hospital authorities granted permission for data collection, thus no further approval or informed consent was needed to undertake this study in both hospitals. However, before the distribution of surveys respondents' participation willingness was inquired. Finally, SPSS (ver. 20) was used in data analyses.

\section{Results}

Demographic profile of participants- Out of 916 participants, a total of 872 residents responded to the surveys with a response rate of $95 \%$. Of these $59 \%(n=517)$ were male and $41 \%(n=355)$ were female resident doctors. The reason why male doctors were greater in participation due to easy access as compared with female doctors. Further, the majority of female doctors refused to participate in this study. However, to avoid gender-based response all surveys were randomly distributed to a convenient sample of residents' doctors in both hospitals. About the hospital affiliation, $43 \%(n=376)$ respondents were from $\mathrm{KTH}$ while $57 \%(n=496)$ from HMC. The reason may be that $\mathrm{HMC}$ is bigger than $\mathrm{KTH}$ in terms of seats of developed specialities. Similarly, age-wise data distribution indicated major participation within the age range of 33-37 years (54\%), followed by 28-32 years (24\%) and 38-42 years (22\%). The reason that respondents in the age-group of 33-37 years are larger than the others may be that most doctors prefer to start the job after completing their house job. Besides, few of the doctors may not be able to pass the FCPS(I) before joining a speciality program which is requisite to become postgraduate resident trainee/doctor. Further, participation by department of speciality indicated $16.4 \%(n=143)$ from general medicine, $11.2 \%(n=98)$ from general surgery, $8 \%(n=68)$ from gynaecology, $9 \%(n=80)$ from paediatrics, $2 \%(n=15)$ from psychiatry, $13 \%(n=111)$ from dermatology, $9 \%(n=77)$ from cardiology, $6 \%(n=50)$ from ophthalmology, $5.3 \%(n=46)$ from radiology, $2 \%(n=14)$ from nephrology, $9 \%(n=75)$ from orthopaedics, $10 \%(n=85)$ from urology, and $1 \%(n=10)$ from pulmonology. The inclusive demographic results showed major participation from the male resident doctors at HMC. Similarly, most of the respondents were in the age range of 33-37 years followed by 28 to 32 years. Moreover, key respondents were specializing in general medicine, followed by dermatology, general surgery and urology. The variations in the number of attachments under different 
specialities are subject to the availability of the number of supervisory slots under the CPSP induction guidelines.

Table 1: Characteristics of the sample $(n=872)$

\begin{tabular}{llll}
\hline Constructs & Indicators & Frequency & $(\%)$ \\
\hline Gender & Male & 517 & 59 \\
Affiliations & Female & 355 & 41 \\
Age groups in years* & Hayatabad Medical Complex-HMC & 496 & 57 \\
& Khyber Teaching Hospital- KTH & 376 & 43 \\
& $30 \pm 3(28$ to 32) & 212 & 24 \\
& $35 \pm 3(33$ to 37) & 468 & 54 \\
Categories of Specialty & General medicine & 192 & 22 \\
& General surgery & 143 & 16 \\
& Gynaecology & 98 & 11 \\
& Paediatrics & 68 & 7.7 \\
& Psychiatry & 80 & 9 \\
& Dermatology & 15 & 2 \\
& Cardiology & 111 & 13 \\
& Ophthalmology & 77 & 9 \\
& Radiology & 50 & 5.7 \\
& Nephrology & 46 & 5 \\
& Orthopaedics & 14 & 2 \\
& Urology & 75 & 8.6 \\
& Pulmonology & 85 & 10 \\
\hline
\end{tabular}

\section{Awareness about plagiarism}

The results in Table 2 showed that $78 \%(n=676)$ of the respondents understand the meaning of plagiarism while $17 \%(n=148)$ don't know. The resident doctors supported the idea that plagiarism must be avoided $(87 \%, \mathrm{n}=760)$ because it is unethical to practice $(76 \%, n=667)$ and plagiarists should be punished $(84 \%, n=736)$. Likewise, plagiarism was perceived as intellectual dishonesty $(81 \%, n=707)$ that negatively impact the research quality $(91 \%, n=796)$. Additionally, plagiarism deterrence is not merely getting knowledge of citation styles $(75 \%, n=657)$, but accurate crediting original authorship through accurate citation patterns $(66 \%, n=579)$. The overall results showed that resident doctors in the hospitals of Peshawar, Pakistan are aware of the concept and consequences of plagiarism. A percentage-wise composite result of the measurement items with counts on awareness about plagiarism has been provided in Figure 1, indicating the residents highest awareness about plagiarism. Further, Figure 1 is the graphical representation of 
data distribution through a line graph to additionally establish resident doctors' highest level of awareness about plagiarism.

Table 2: Residents' awareness about plagiarism $(n=872)$

\begin{tabular}{llllllll}
\hline Items & Items & SD & $\mathrm{D}$ & $\mathrm{N}$ & $\mathrm{A}$ & $\mathrm{SA}$ & $\mathrm{M}$ \\
\hline Item1 & understand the meaning of plagiarism & 125 & 23 & 48 & 265 & 411 & 3.84 \\
Item2 & avoiding plagiarism is mandatory & 37 & 13 & 62 & 301 & 459 & 3.79 \\
Item3 & recognize plagiarism is wrong & 26 & 22 & 157 & 279 & 388 & 3.65 \\
Item4 & plagiarism is intellectual dishonesty & 62 & 101 & 2 & 363 & 344 & 2.73 \\
Item5 & understand plagiarism is punishable & 21 & 43 & 72 & 239 & 497 & 3.07 \\
Item6 & knowing only citing sources of data & 417 & 240 & 49 & 10 & 156 & 3.11 \\
Item7 & accuracy in citation is vital for deterrence & 41 & 71 & 181 & 310 & 269 & 2.99 \\
Item8 & plagiarism harms quality of research & 6 & 56 & 14 & 367 & 429 & 2.04 \\
\hline SD-strongly disagree, D-Disagree $N$-neutral, SA-strongly agree, A-agree, M- Mean
\end{tabular}

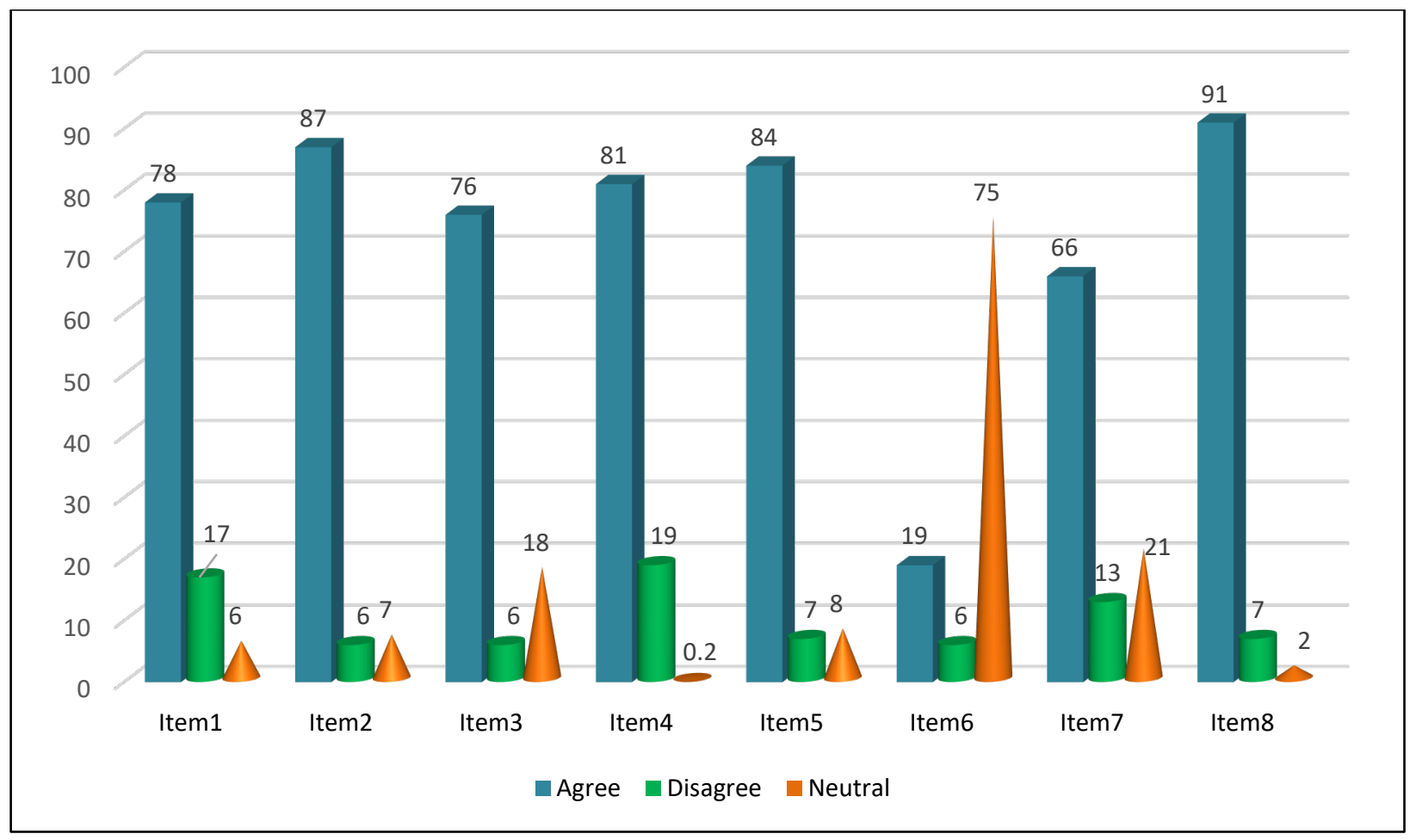

Figure 1: Item-wise composite results of residents' awareness about plagiarism 
Besides, to compare residents' awareness about plagiarism based on demographics (hospitals of speciality, gender and age) the below three null hypotheses were formulated:

$\mathrm{H}_{01}$ : There is no statistically significant difference in awareness of residents about plagiarism and their category speciality;

Ho2: There is no statistically significant difference in awareness of residents about plagiarism based on gender;

$\mathrm{H}_{03}$ : There is no statistically significant difference in residents' awareness about plagiarism based on age;

To examine $\mathrm{H}_{01}$, independent sample $\mathrm{t}$-test was conducted (as there are two groups). As shown in Table 3, the results of the mean score of two groups revealed a statistically significant difference $(\alpha=.022, \mathrm{p}<0.05)$ and thus $\mathrm{H}_{01}$ is rejected. The findings further showed that level of awareness about plagiarism among the residents of HMC $(M=3.83, S D=.937)$ is higher than the doctors in the KTH $(M=3.41, S D=.204)$.

Table 3: Results of t-test regarding awareness about plagiarism vs hospital of a speciality

\begin{tabular}{l|lllllll}
\hline $\begin{array}{l}\text { Awareness } \\
\text { about } \\
\text { plagiarism }\end{array}$ & $\begin{array}{l}\text { Hospital of } \\
\text { speciality }\end{array}$ & $\mathrm{n}$ & $\mathrm{M}$ & $\mathrm{SD}$ & $\mathrm{t}$ & $\mathrm{df}$ & $\begin{array}{l}\text { t-test sig. } \\
\text { (2-tailed) }\end{array}$ \\
\cline { 2 - 7 } & $\begin{array}{l}\text { Khyber Teaching } \\
\begin{array}{l}\text { Hospital-KTH } \\
\text { Hayatabad Medical } \\
\text { Hospital-HMC }\end{array}\end{array}$ & 396 & 3.41 & .204 & -.822 & 3.201 & $.022^{*}$ \\
\hline
\end{tabular}

* Significant at 0.05 level

Similarly, to test $\mathrm{H}_{02}$ independent sample t-test was conducted (as there are two groups). As shown in Table 4, the results of the mean score of two groups revealed a statistically insignificant difference $(\alpha=.711, \mathrm{p}>0.05)$ and thus $\mathrm{H}_{02}$ is supported. The findings further showed that level of awareness among the female resident doctors $(M=3.82, S D=.112)$ is higher than the male residents $(M=3.11, S D=.501)$.

Table 4: Results of t-test regarding awareness about plagiarism vs respondents' gender

\begin{tabular}{l|lllllll}
\hline $\begin{array}{l}\text { Awareness about } \\
\text { plagiarism }\end{array}$ & Gender & $\mathrm{n}$ & $\mathrm{M}$ & $\mathrm{SD}$ & $\mathrm{t}$ & $d f$ & $\begin{array}{l}\mathrm{t} \text {-test sig. } \\
\text { (2-tailed) }\end{array}$ \\
\cline { 2 - 8 } & Male & 517 & 3.11 & .112 & .603 & .625 & $.711^{*}$ \\
& Female & 355 & 3.82 & .501 & & & \\
\hline
\end{tabular}

*Significant at 0.05 level 
Furthermore, one-way ANOVA was conducted to explore the impact of age on residents' levels of awareness about plagiarism. The study respondents were categorized into three age groups (28-32 years; 33-37 years and 38-42 years). As shown in Table 5, the difference was found statistically significant $(\alpha=.001, \mathrm{p}<0.05)$ and thus $\mathrm{H}_{03}$ is rejected. The results further indicated that level of awareness about plagiarism among the residents of age group 28-32 years is higher $(M=3.95, S D=.71)$ than the age groups 33-37 years $(M=3.88, S D=.62)$ and $38-42$ years $(M=3.41, S D=.51)$.

Table 5: Results of One-way ANOVA about plagiarism awareness vs respondents' age

\begin{tabular}{|c|c|c|c|c|c|c|c|c|}
\hline \multirow{4}{*}{$\begin{array}{l}\text { Awareness about } \\
\text { plagiarism }\end{array}$} & \multicolumn{5}{|c|}{ Mean } & \multirow[t]{2}{*}{$F$} & \multirow[t]{2}{*}{$d f$} & \multirow[t]{2}{*}{ Sig } \\
\hline & $\begin{array}{l}28-32 \\
\text { years }\end{array}$ & $\begin{array}{l}33-3 \\
\text { years }\end{array}$ & & $\begin{array}{l}38-4 \\
\text { years }\end{array}$ & & & & \\
\hline & $M \quad S D$ & $M$ & SD & M & SD & 4.552 & (2.447) & $.001^{*}$ \\
\hline & $\begin{array}{ll}3.95 & .71\end{array}$ & 3.88 & .62 & 3.41 & .51 & .251 & & \\
\hline
\end{tabular}

* Significant at 0.05 level

\section{Understanding the definition of plagiarism}

The results in Table 6 exhibited that $86 \%(n=752)$ of the respondents were found agreed that plagiarism is defined as using others' work as own, followed by intentional or unintentional use of published or unpublished works or ideas $(84 \%, n=733)$, paraphrasing without crediting sources $(82 \%, n=714)$, copying as a whole or in parts without citation $(79 \%, n=691)$, use of the information without quotations $(78 \%, n=684)$, using online or printed data without crediting the original author $(75 \%, n=656)$, and knowingly use of data without quotation $(63 \%, n=549)$. Although, the overall findings established that postgraduate resident doctors understand the definition of plagiarism, but still significant variations were found. However, results showed that variations in the definition of plagiarism were found and is represented graphically in Figure 2. Figure 2 shows percentage-wise composite results of each measurement item with counts on the definition of plagiarism, indicating highly adopted definition among the respondents (Item 4).

Table 6: Resident doctors' understanding of the definition of plagiarism

\begin{tabular}{llllllll}
\hline Items & Items & SD & D & N & A & SA & M \\
\hline Item1 & copying whole or parts without citation & 67 & 107 & 7 & 218 & 473 & 3.88 \\
Item2 & stealing online or printed data & 137 & 56 & 23 & 187 & 469 & 3.06 \\
\hline
\end{tabular}




\begin{tabular}{llllllll}
\hline Item3 & paraphrasing without crediting sources & 23 & 204 & 31 & 346 & 268 & 3.51 \\
Item4 & using others' works as own (crime) & 78 & 23 & 19 & 427 & 325 & 3.23 \\
Item5 & knowingly cheating of information & 204 & 36 & 83 & 367 & 182 & 2.67 \\
Item6 & $\begin{array}{l}\text { Use of information without quotation } \\
\text { Item7 }\end{array}$ & 31 & 111 & 46 & 275 & 409 & 2.31 \\
& $\begin{array}{l}\text { intentional or unintentional adaptation of } \\
\text { published or unpublished works as own }\end{array}$ & 39 & 87 & 13 & 411 & 322 & 2.03 \\
\hline
\end{tabular}

SD-strongly disagree, D-Disagree N-neutral, SA-strongly agree, A-agree, M- Mean

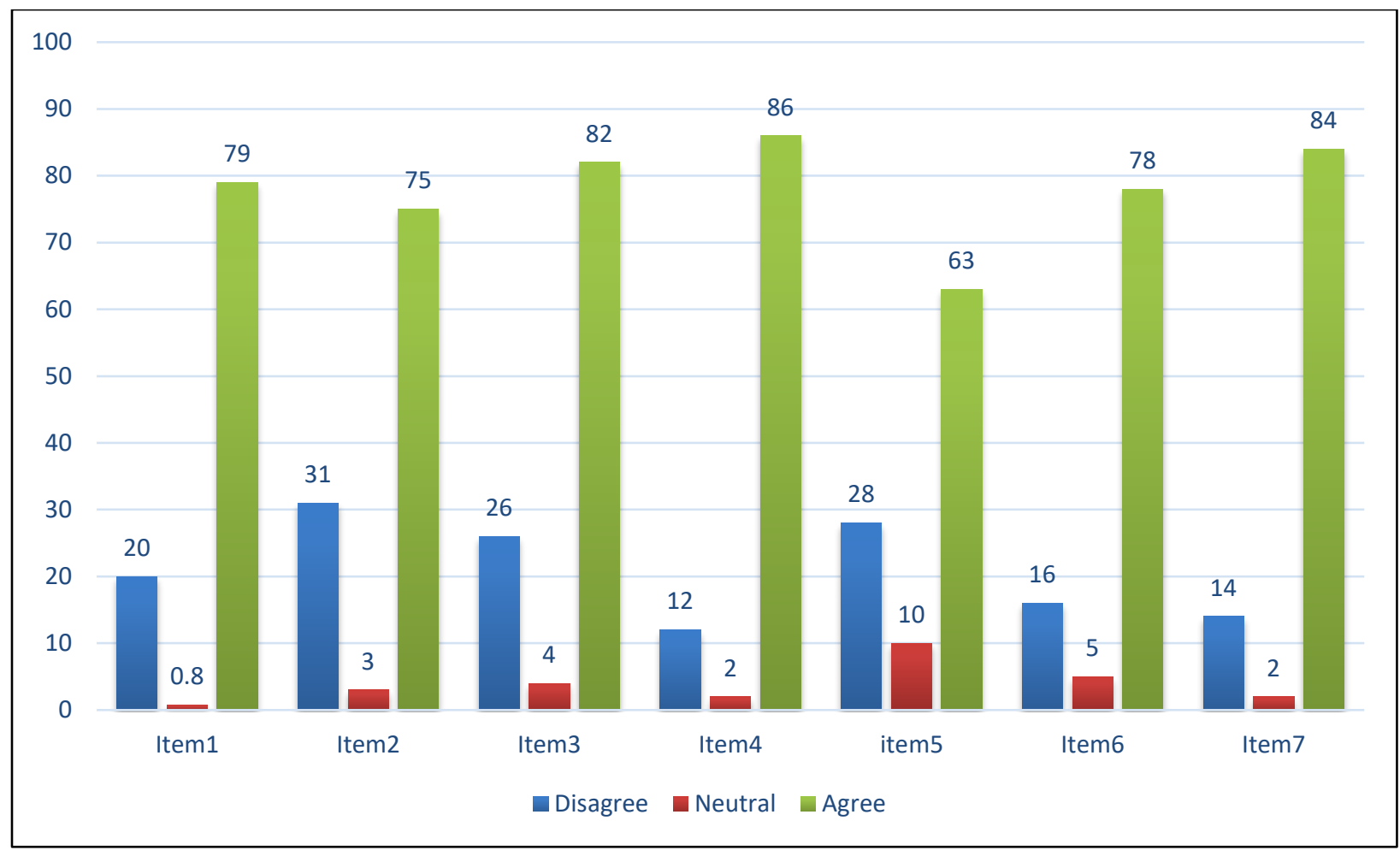

Figure 2: Bar graph of response variation regarding the understanding of the definition of plagiarism

\section{Familiarity with anti-plagiarism policies}

As shown in Table 7, 64\% $(n=556)$ of the doctors were agreed that CPSP has strict antiplagiarism policies. Further, a similar percentage of respondents argued that CPSP is the only body that liable to implement plagiarism deterrence policies. However, 30\% ( $n=260)$ of the residents dissented that CPSP is not serious about the strict implementation of plagiarism prevention policies. Further, $71 \%(n=623)$ of the respondents established supervisors as the only implementer of anti-plagiarism policies. Moreover, the results are alarming in the context of librarians where $77 \%(n=675)$ of the respondents showed disagreement with the statement that librarians helped them in the circumvention of plagiarism. Only $22 \%(n=193)$ of the respondents were agreed that librarians guide them on how to avoid plagiarism. The results also indicated that several respondents $(74 \%$, 
$\mathrm{n}=649$ ) never attended any seminars on anti-plagiarism policies. The inclusive results recognized that doctors understand about the CPSP provided anti-plagiarism policies, its implementation process and role of librarians' and their research supervisors towards the deterrence of plagiarism. The response variations regarding plagiarism policies have been shown graphically in Figure 3. Figure 3 showed the percentage-wise composite results with counts on anti-plagiarism policies.

Table 7: Resident doctors' familiarity with anti-plagiarism policies

\begin{tabular}{llllllll}
\hline Items & Statements about plagiarism policies & DA & D & N & A & SA & M \\
\hline Item 1 & CPSP has strict policies & 167 & 93 & 56 & 287 & 269 & 3.91 \\
Item 2 & CPSP implement plagiarism policies & 121 & 153 & 43 & 296 & 259 & 3.61 \\
Item 3 & supervisor implement policies & 147 & 85 & 17 & 422 & 201 & 3.44 \\
Item 4 & librarians guide about policies & 353 & 322 & 4 & 128 & 65 & 2.37 \\
Item 5 & plagiarism means reject research & 269 & 87 & 33 & 361 & 122 & 2.11 \\
Item 6 & attended seminars on policies & 431 & 218 & 78 & 92 & 53 & 2.08 \\
\hline
\end{tabular}

$S D$-strongly disagree, $D$-Disagree $N$-neutral, SA-strongly agree, A-agree, M- Mean

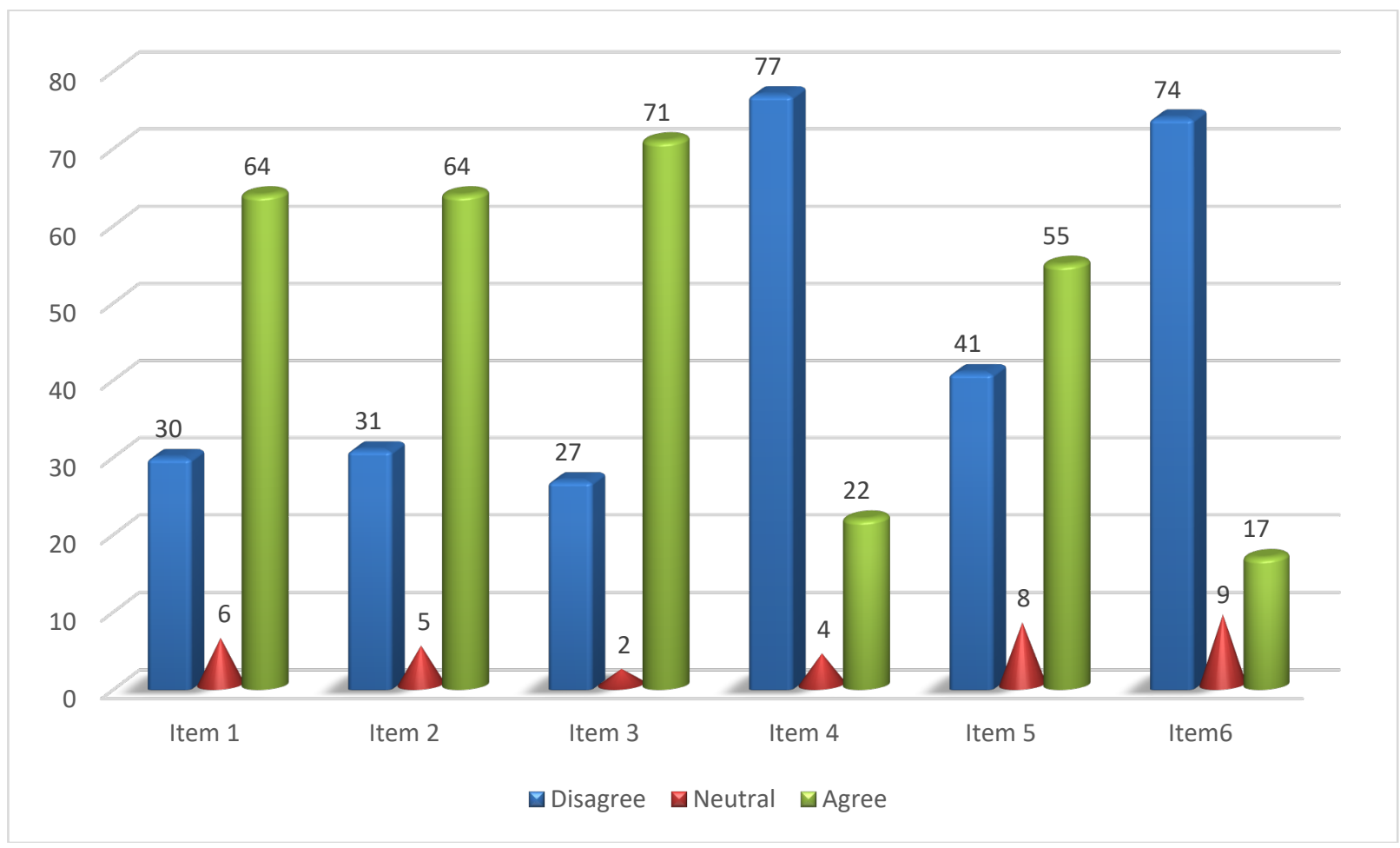

Figure 3: Bar graph of residents' response variation regarding plagiarism policies

\section{Effectiveness of library IL program}


As indicated in Table $8,76 \%(n=666)$ of the resident doctors understand that librarians are responsible to offer IL activities. However, few residents indicated disagreement with the statement that librarians have arranged IL activities. Likewise, 83\% $(n=726)$ were found unsatisfied with the role of IL activities toward the prevention of plagiarism. Similarly, $94 \%(n=819)$ of the respondents reported that library IL program is not teaching them accurate use of citation styles (Item 3). Moreover, 83\% $(n=726)$ of the respondents revealed disagreement with the statement that librarians instruct about the use of citation software. Likewise, $85 \%(n=742)$ claimed that librarians never informed them about the significances of correct citation. Likewise, $93 \%(n=810)$ respondents were found disagree with the notion that library IL program assists in the use of digital resources. Also, $91 \%(n=790)$ respondents mentioned that librarians never organize training or workshop on research writing skill. Regarding the collaboration between research supervisors and librarians, only $34 \%(n=300)$ of the respondents affirmed the existence of this practice. The inclusive results recognized that doctors are not satisfied with the role of library IL program towards the deterrence of plagiarism. Further, response variations regarding the effectiveness of library IL programs in the deterrence of plagiarism have been graphically provided in Figure 4 .

Table 8: Effectiveness of library IL program in the deterrence of plagiarism

\begin{tabular}{lllllll}
\hline Items & Measurement items & SD & D & N & A & SA \\
\hline Item 1 & responsible to teach information literacy skills & 113 & 83 & 10 & 369 & 297 \\
Item 2 & provide instructions to deter plagiarism & 456 & 270 & 5 & 37 & 104 \\
Item 3 & guide you in the accurate use of citation styles & 195 & 624 & 13 & 29 & 11 \\
Item 4 & instruct you about citation software & 424 & 302 & 7 & 83 & 56 \\
Item 5 & explain the importance of citing sources & 614 & 128 & 2 & 104 & 24 \\
Item 6 & help in the proper use of digital resources & 563 & 247 & 7 & 39 & 16 \\
Item 7 & organize training on writing skills & 475 & 315 & 11 & 27 & 44 \\
Item 8 & collaborate with supervisor to deter plagiarism & 258 & 103 & 211 & 121 & 179 \\
\hline
\end{tabular}

$S D$-strongly disagree, D-Disagree N-neutral, SA-strongly agree, A-agree, $M$ - Mean 


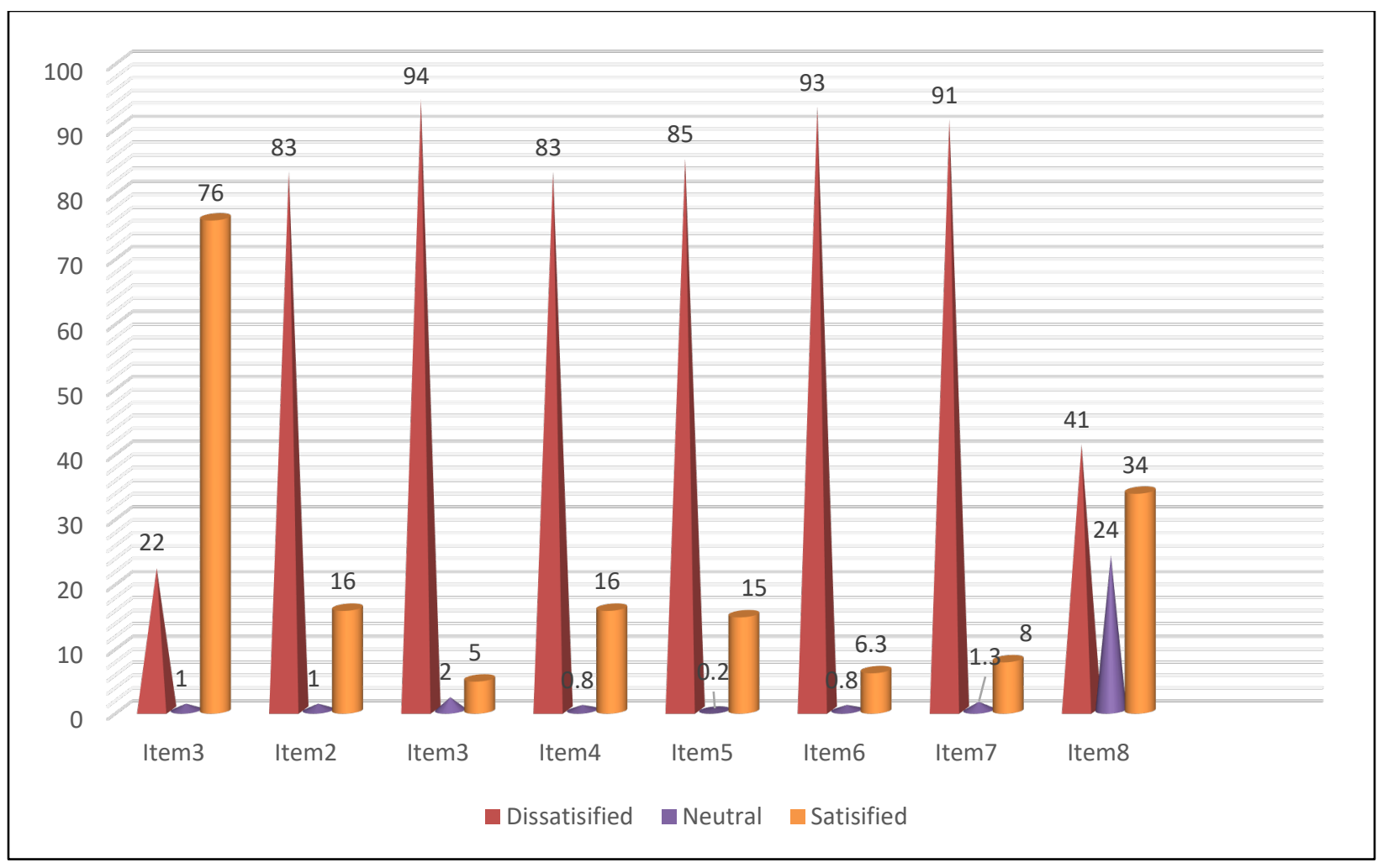

Figure 4: Line graph of response variations regarding the IL program

To compare the effectiveness of library IL program in the prevention of plagiarism based on demographics (resident' hospitals, gender, and department of speciality), the following null hypotheses were formulated.

$\mathrm{H}_{04}$ : There is no statistically significant difference in the role of library IL program towards prevention of plagiarism based on residents' hospital;

$\mathrm{H}_{05}$ : There is no statistically significant difference in the role of library IL program towards prevention of plagiarism based on residents' gender;

Ho6: There is no statistically significant difference in the role of library IL program towards prevention of plagiarism based on the department of speciality

To examine $\mathrm{H}_{04}$, independent sample t-test was conducted. As shown in Table 9, the results of the mean score of two groups revealed a statistically significant difference with an alpha value of 0.05 and thus $\mathrm{H}_{04}$ is rejected. The findings showed that the level of effectiveness of the library IL program in the deterrence of plagiarism among the resident doctors of $\mathrm{KTH}(M=3.91, S D=.312)$ is higher than HMC $(M=3.37, S D=.823)$.

Table 9: Results of t-test on the effectiveness of IL program vs residents' hospital 


\begin{tabular}{|c|c|c|c|c|c|c|c|}
\hline \multirow{2}{*}{$\begin{array}{l}\text { Effectiveness } \\
\text { of IL program }\end{array}$} & $\begin{array}{l}\text { Hospital of } \\
\text { speciality }\end{array}$ & $n$ & $M$ & SD & $\mathrm{t}$ & $d f$ & $\begin{array}{l}\text { t-test sig. } \\
\text { (2-tailed) }\end{array}$ \\
\hline & $\begin{array}{l}\text { Khyber Teaching } \\
\text { Hospital-KTH } \\
\text { Hayatabad Medical } \\
\text { Hospital-HMC }\end{array}$ & $\begin{array}{l}496 \\
376\end{array}$ & $\begin{array}{l}3.91 \\
3.37\end{array}$ & $\begin{array}{l}.312 \\
.823\end{array}$ & -.745 & 3.314 & $.031^{*}$ \\
\hline
\end{tabular}

* Significant at 0.05 level

To test $\mathrm{H}_{05}$, independent sample t-test was conducted. As shown in Table 10, the results of the mean score of two groups revealed a statistically significant difference $(\alpha=.031, p<0.05)$ and thus $H_{05}$ is rejected. However, findings further showed that level of effectiveness of library IL program in the prevention of plagiarism among the male resident doctors $(M=3.67, S D=.214)$ is higher than female $(M=3.32, S D=.311)$.

Table 10: Results of t-test on the effectiveness of library IL program vs gender

\begin{tabular}{l|lllllll}
\hline $\begin{array}{l}\text { Awareness } \\
\text { about } \\
\text { plagiarism }\end{array}$ & Gender & $\mathrm{n}$ & $\mathrm{M}$ & $\mathrm{SD}$ & $\mathrm{t}$ & $d f$ & $\begin{array}{l}\text { t-test sig. } \\
\text { (2-tailed) }\end{array}$ \\
\cline { 2 - 8 } & Male & 517 & 3.67 & .214 & .742 & .581 & $.002^{*}$ \\
& Female & 355 & 3.32 & .311 & & & \\
\hline
\end{tabular}

* Significant at 0.05 level

To test $\mathrm{H}_{06}$, one-way ANOVA test was conducted to examine the impacts of the departments of speciality on the effectiveness of library IL program in the prevention of plagiarism. The study respondents were categorized into thirteen departments of speciality. Most of the results as shown in Table 11, indicated a statistically significant difference with an alpha value of 0.05 and thus $\mathrm{H}_{06}$ is rejected. However, few results were found insignificant, and thus $\mathrm{H}_{06}$ is supported. 
Table 11: Results of One-way ANOVA on the effectiveness of IL programs vs categories of speciality

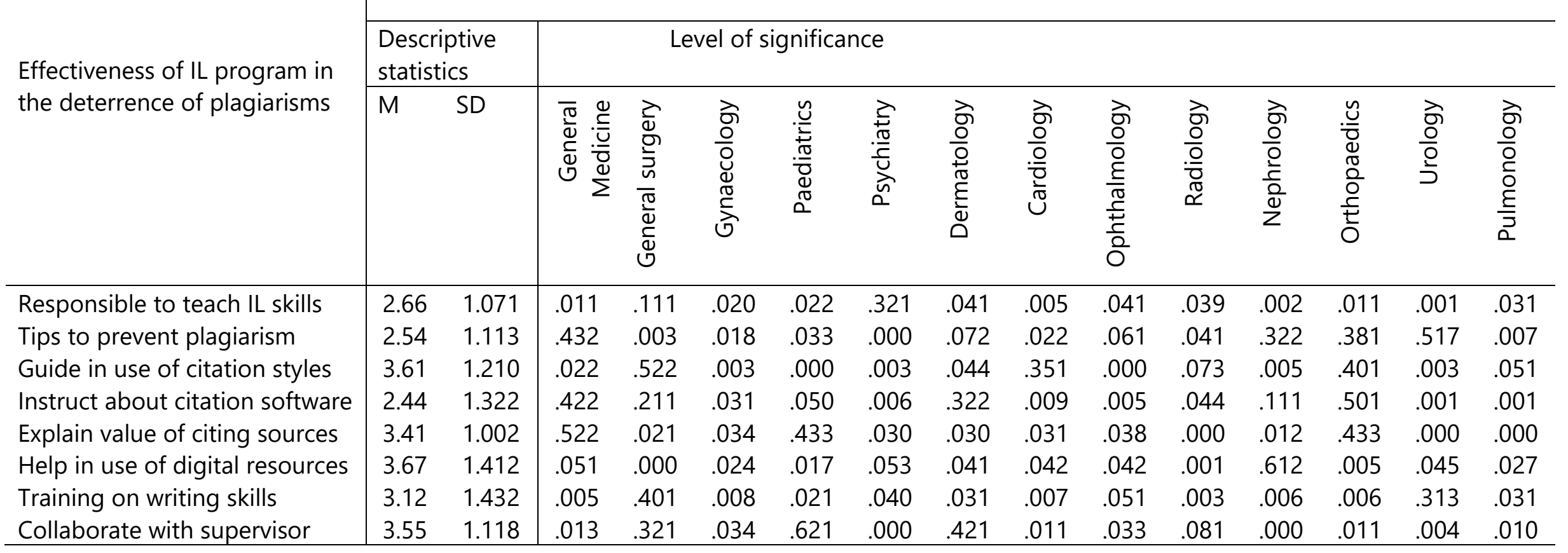




\section{Discussion}

The importance of research in addressing global challenges cannot be understated. In looking at research environments, research integrity is a fundamental pillar. As a corollary, integrity is equally as important in those academic organizations at which researchers undertake their undergraduate and (post)graduate studies. In a recent advice paper (2020), the League of European Research Universities (LERU) has boldly stated that

The excellence of, and trust in, research produced by universities is inherently linked to the integrity of their researchers. Given that the research process increasingly involves collaboration that transcends disciplinary, institutional and national boundaries, universities have a collective responsibility in developing and implementing a research and educational environment which supports research integrity, thereby maintaining and strengthening confidence in their researchers' work (p. [3]).

Every country and university will have its own challenges in striving to meet these goals. Research and academic integrity share several common elements, of which plagiarism is one. Pakistan is useful as an exemplar of a developing country confronting these challenges because of not only the documented general lack of interest within higher education in regard to plagiarism but also its implications for an important area of research, namely, medical science.

As in the case of the initial study of plagiarism in Pakistan by Shirazi (2010), the results of the current study, although limited to two teaching hospitals in Peshawar, are indicative of a problem that exists nationwide within the medical community. The study is the first to analyze Pakistani postgraduate resident doctors in regard to their perception and use of plagiarism. It is significant because it examines this environment in the context of two national initiatives: (1) the general anti-plagiarism policy of the Higher Education Commission Pakistan and (2) the specific requirements of the College of Physicians and Surgeons Pakistan (CPSP), including advice about plagiarism.

As indicated above, postgraduate resident doctors are required to write research dissertations to qualify for the CPSP final examination. In addition, during their training period, residents must publish and/or present case study reports in either peer reviewed or CPSP recognized journals. The findings, which support the results of Abukari (2016) and Khemiss et al. (2019), revealed that while resident doctors were aware of the concept of plagiarism, there were variations in their definition of the term. They perceived plagiarism as an unethical practice and supported the implementation of anti-plagiarism policies. However, the respondents' knowledge was not strong regarding citation styles, specific anti-plagiarism policies, and plagiarism penalties. These findings support the results of Gullifer and Tyson (2014) that anti-plagiarism policies were never explained to 
researchers. In the context of developing a responsible research culture characterized by integrity, these overall findings are of concern. There is a clear disconnect between written policies and actual practice.

Given the importance of plagiarism prevention strategies and the specific benefit that library information literacy activities can contribute, the researchers also surveyed the respondents as to their perceptions of the effectiveness of library IL programs in the prevention of plagiarism. The findings showed a statistically significant level of dissatisfaction among respondents. The two main areas of dissatisfaction can be categorized broadly as service delivery and program content.

While respondents generally agreed that the library in each of the teaching hospitals was responsible for teaching information literacy skills, a high percentage of respondents indicated that the library did not actually organize workshops or other types of training sessions on research writing skills. Approximately seventy per cent reported that there was no collaboration between librarians and the research supervisor to assist this cohort with plagiarism prevention; this supports the findings of Michalak et al. (2018) that faculty tended not to invite librarians into their classrooms to teach about this topic. Although based on the survey results, the researchers have inferred that there is some IL skills instruction within the two libraries, a large number of respondents indicated that the library was not instructing them in those basic IL skills which have an inherent connection with plagiarism, e.g. the importance of / rationale for citation and the appropriate use of citation software, citation styles, and digital resources.

On this basis, the researchers would suggest several strategies to address the issues raised by the survey results. The overarching framework should be based on collaboration among the key stakeholders, which would include resident doctors, research supervisors and librarians. This approach is to help ensure the delivery of consistent messages and to reinforce the importance of the topic.

Rathore et al. (2015) has logically suggested that the CPSP can take strict action against plagiarism and enforce its policies. However, based on the research reported in this current study, it may also be sensible to encourage the CSPS to organize a national workshop of key stakeholders in medical education to determine what role each of them can play in achieving research / academic integrity, including training delivery. Plagiarism would necessarily be an integral part of the discussion.

At the same time, Shirazi et al. (2010) have suggested that institutions and doctors are jointly liable for the prevention of plagiarism. This is an ideal opportunity for the library to promote collaboration, as Michalak et al. (2018) have discussed. As at the national level, ideally, the collaboration would be contextualised on the basis of the broader challenge of research / academic integrity but including plagiarism as a key component. The 
stakeholders would work together to develop an agreed communication plan and training program, with each party contributing their particular expertise. It is within this framework that the library would logically include IL training. Ultimately, there should be a shared understanding of how this collaborative effort would substantially modify a current culture which lacks effective plagiarism deterrence.

The results of the current study raise questions as to why the two hospital libraries were not formally teaching several important IL skills, including plagiarism prevention. Further research is indicated on possible barriers. If one barrier is a lack of confidence in competency and this perception is shared by librarians in other institutions, then there may be a potential role for national library bodies, e.g. the Pakistan Library Association (PLA). For example, it could collaborate with relevant LIS faculties to organize workshops, designed to provide hands-on instruction for librarians in key IL skills.

\section{Implications for library IL program}

As stated above, several resident doctors still are not familiar with the library IL program, thus health librarians can restructure their IL programs. In this regard, a special focus is required on foremost elements specifically stable marketing strategy and frequent revision of IL activities/contents. In addition, as doctors' understanding of the definition of plagiarism is fluctuating, thus librarians can teach the doctors about the CPSP definition of plagiarism to ensure homogeneity in its comprehension. Since many doctors affirmed their unfamiliarity about library IL role towards prevention of plagiarism, thus there is an opportunity for collaboration between librarians, medical research supervisors. Such collaborations perhaps facilitate librarians and CPSP to jointly organize IL programs regarding multiple aspects of the research. Through these IL activities, librarians can teach doctors about how to conduct accurate research adopting suitable methods. Through IL programs librarians can teach the doctors how to accurately cite the original authorship, what types of software are currently in use for the prevention of plagiarism. Librarians can give increased consideration to the doctors' information-seeking skills and then teaching them its ethical and legal utilization in further research projects. As findings of this study established unfamiliarity of resident doctors with library IL program, thus it is evident to develop a stable IL program with contemporary contents on plagiarism in health libraries to deter plagiarism. These evidences further necessitate a stable collaboration on research integrity among the medical faculty and librarians to guide them towards the use of plagiarism prevention resources in libraries. A speciality-specific collaboration between the medical faculty, supervisors and librarians can be significant to make a connection between doctors' research needs and library IL programs.

\section{Limitations and future research of the study}

The findings of this study should be interpreted in light of certain limitations that can be predicted as opportunities for future research. Since, plagiarism was examined 
based on CPSP anti-plagiarism policies in the perspective of resident doctors, thus similar study can be conducted keeping in view social and economic barriers to access information resources. Also, it is significant to evaluate the current quality of IL activities and CPSP research facilities provided to these doctors. Further, research is required to evaluate barriers to the successful implementation of CPSP anti-plagiarism policies at the national level. Also, there is a possibility of similar results at the national level, thus the same study with or without additional factors may be significant at the national level. Besides, it is librarians' ethical and legal responsibility to combat against the plagiarism particularly in the context of electronic resources. Lastly, it is significant to investigate the barriers faced by health librarians in the marketing of IL programs of which the majority of doctors are not familiar, teaching of anti-plagiarism policies and overall prevention of plagiarism.

\section{Conclusion}

Plagiarism undermines intellectual integrity, research ethics, and the quality of research. It is anathema to responsible research culture. The authors surveyed the level of knowledge about plagiarism, anti-plagiarism policies, and prevention strategies among postgraduate resident doctors in Peshawar, Pakistan. From a positive perspective, results showed that this cohort was aware of the concept of plagiarism, even if they did not necessarily define it uniformly. However, the respondents' knowledge was not strong regarding citation styles, specific anti-plagiarism policies, and plagiarism penalties. In examining the effectiveness of hospital library IL programs in the prevention of plagiarism among resident doctors, the authors found a high level of dissatisfaction. Additional beneficial insights could be gained by expanding the survey to include a larger sample of resident doctors nationwide as well as the librarians who support them. The overall findings of the current study, along with suggested remediation strategies, are applicable

to other health libraries worldwide that wish to address the challenge of plagiarism among health researchers in general.

\section{References}

Abasi, A.R., and Graves, B. (2008), "Academic literacy and plagiarism: conversations with international graduate students and disciplinary professors", Journal of English for Academic Purposes, Vol. 7 No. 4, pp. 221-233.

Abdullah, J.M., (2014), "The eight stages of trust and "Amanah" in medicine and the Dunning-Kruger effect" Malaysian Journal of Medical Science, Vol. 21 No. 4, pp.1-3.

Abukari, Z. (2016), "Awareness and incidence of plagiarism among students of higher education: a case study of Narh-Bita College (Master dissertation, University of Ghana), available at http://197.255.68.203/handle/123456789/21270 (accessed February 22, 2020) 
Akbulut, Y., Şendağ, S., Birinci, G., Kilicer, K., Sahin, M.C., and Odabasi, H.F. (2008), "Exploring the types and reasons of Internet-triggered academic dishonesty among Turkish undergraduate students: development of internet-triggered academic dishonesty scale (ITADS)", Computers \& Education, Vol. 51 No. 1, pp. 463-473.

Anney, V.N., and Mosha, M.A. (2015), "Student's plagiarisms in higher learning institutions in the era of improved Internet access: a case study of developing countries", Journal of Education and Practice, Vol. 6 No. 13, pp. 203-216.

Ayre, S., Barbook, J., Engel, C., Lacey, P., Phul, A., Stevenson, P., and Toft, S. (2014), "Measuring the impact of information skills training: a survey of health libraries in England", Health Information \& Libraries Journal, Vol. 32, pp. 50-60. https://doi.org/10.1111/hir.12079

Batane, T. (2010), "Turning to Turnitin to fight plagiarism among university students", Journal of Educational Technology \& Society, Vol. 13 No. 2, pp. 1-12.

Bell, S. (2018), "Addressing student plagiarism from the library learning commons", Information and Learning Sciences, Vol. 119 No. 3/4, pp. 203-214

Bilić-Zulle, L., Frković, V., Turk, T., Ažman, J., \& Petrovečki, M. (2005), "Prevalence of plagiarism among medical students", Croatian Medical Journal, Vol. 46 No. 1, pp. 126-131.

Burger, A. (2018), "Reframing anti-plagiarism efforts in the academic library", Georgia Library Quarterly, Vol. 55 No. 1, article 11, pp. 1-5.

Cheema, Z.A., Mahmood, S.T., Mahmood, A., and Shah, M. A. (2011), "Conceptual awareness of research scholars about plagiarism at higher education level: intellectual property right and patent", International Journal of Academic Research, Vol. 3 No. 1, pp. 665-670.

Chen, Y., and Chou, C. (2017), "Are we on the same page? college students' and faculty's perception of student plagiarism in Taiwan", Ethics \& Behaviour, Vol. 27 No. 1, pp. 53-73.

Childers, D., \& Bruton, S. (2016), "Should it be considered plagiarism?' student perceptions of complex citation issues", Journal of Academic Ethics, Vol. 14 No. 1, pp. 1-17.

Creswell, J.W. and Zhang, W. (2008), "The application of mixed methods designs to trauma research", Journal of Traumatic Stress, Vol. 22 No. 6, pp. 612-621.

Derby, B. (2008), "Duplication and plagiarism increasing among students", Nature, Vol. 452, pp. 29-30. https://doi.org/10.1038/452029c 
Devlin, M., and Gray, K. (2007), "In their own words: a qualitative study of the reasons Australian university students plagiarize", Higher Education Research \& Development, Vol. 26 No. 2, pp.181-198.

Duff, A.H., Rogers, D.P., and Harris, M.B. (2006), "International engineering studentsavoiding plagiarism through understanding the Western academic context of scholarship", European Journal of Engineering Education, Vol. 31 No. 6, pp. 673-681.

East, J. (2010), "Judging plagiarism: a problem of morality and convention", Higher Education, Vol. 59 No.1, pp. 69-83.

Elzubeir, M.A., and Rizk, D.E. (2003), "Exploring perceptions and attitudes of senior medical students and interns to academic integrity", Medical Education, Vol. 37 No. 7, pp. 589-96.

Fishman, T., ed. (2014), The fundamental values of academic integrity. $2^{\text {nd }}$ ed., International Centre for Academic Integrity, Clemson, SC.

Fister, B. (1992), "Common ground: The composition/bibliographic instruction connection" in Kirk, T. (Ed.), Academic libraries: Achieving excellence in higher education, ACRL, Chicago, pp. 154-158.

Foltýnek, T., \& Glendinning, I. (2015), "Impact of policies for plagiarism in higher education across Europe: Results of the project", Acta Universitatis Agriculturae et Silviculturae Mendelianae Brunensis, Vol. 63 No. 1, pp. 207-216

Gibson, N.S. and Chester-Fangman, C. (2011), "The librarian's role in combating plagiarism," Reference Services Review, Vol. 39, no. 1, pp. 132-150

Gilmore, J., Strickland, D., Timmerman, B.E., Maher, M. and Feldon, D. (2010), "Weeds in the flower garden: an exploration of plagiarism in graduate students' research proposals and its connection to enculturation, ESL, and contextual factors", International Journal for Educational Integrity, Vol. 6 No. 1, pp. 13-28.

Gullifer, J.M. and Tyson, G.A. (2014), "Who has read the policy on plagiarism? unpacking students' understanding of plagiarism", Studies in Higher Education, Vol. 39 No. 7, pp. $1202-1218$.

Gunnarsson, J., Kulesza, W. J. and Pettersson, A. (2014), "Teaching international students how to avoid plagiarism: librarians and faculty in collaboration", The Journal of Academic Librarianship, Vol. 40 No. 3-4, pp. 413-417. 
Handa, N. and Power, C. (2005), "Land and discover: a case study investigating the cultural context of plagiarism", Journal of University Teaching \& Learning Practice, Vol. 2 No. 3, pp. 65-84. https://ro.uow.edu.au/jutlp/vol2/iss3/8

Harper, M.G. (2006), "High tech cheating", Nurse Education in Practice, Vol. 6 No. 6, pp. 364-371.

Helgesson, G., \& Eriksson, S. (2015), "Plagiarism in research", Medicine, Health Care and Philosophy, Vol. 18 No. 1, pp. 91-101

Hodges, A., Bickham, T., Schmidt, E. and Seawright, L. (2017), "Challenging the profiles of a plagiarist: a study of abstracts submitted to an international interdisciplinary conference", International Journal of Educational Integrity, Vol. 13 No. 7, pp. 1-15.

Hosny, M., and Fatima, S. (2014), "Attitude of students towards cheating and plagiarism: a university case study", Journal of Applied Sciences, Vol. 14 No. 8, pp. 748-757.

Hu, G., \& Sun, X. (2017), "Institutional policies on plagiarism: The case of eight Chinese universities of foreign languages/international studies", System, Vol. 66 June, pp. 5668

Idiegbeyan-Ose, J., Ifijeh, G., Segun-Adeniran, C. D., Esse, U. C., \& Owolabi, S. (2019, "Towards curbing plagiarism in higher institutions of learning: The strategic role of the library", Library Philosophy \& Practice, article 2114, pp. 3-14.

Ismail, K. H. (2018), "Perceptions of plagiarism among medical and nursing students in Erbil, Iraq", Sultan Qaboos University Medical Journal, Vol. 18, No. 2, e196-e201.

Ison, D. C. (2018), "An empirical analysis of differences in plagiarism among world cultures", Journal of Higher Education Policy and Management, Vol 40 No 4, pp. 291304.

Javaeed A., Khan A.S., Khan S.H. and Ghauri S.K., (2019), "Perceptions of plagiarism among undergraduate medical students in Rawalpindi, Pakistan", Pakistan Journal of Medical Sciences, Vol. 35 No. 2, pp. 532-536.

Khemiss, M., Berrezouga, L., Ben Khelifa, M., Masmoudi, T., and Ben Saad, H. (2019), "Understanding of plagiarism among North-African university hospital doctors (UHDs): a pilot study", Accountability in Research, Vol. 26 No. 2, pp. 65-84

Kumar, M., Talib, S.A., and Ramayah, T. (2013), Business research methods, Oxford Fajar, Shah Alam, Malaysia.

Maxel, O.J.M. (2013), "Plagiarism: the cancer of East African University Education", Journal of Education and Practice, Vol. 4 No. 17, pp. 133-143. 
McClurg, C., Powelson, S., Lang, E., Aghajafari, F. and Edworthy, S. (2015), "Evaluating the effectiveness of small group information literacy instruction for undergraduate medical education students using a pre- and post-survey study design", Health Information \& Libraries Journal, Vol. 32 No. 2, pp. 120-130. https://doi.org/10.1111/hir.12098

Michalak, R. Rysavy, M., Hunt, K., Smith, B. and Worden, J. (2018), "Faculty perceptions of plagiarism: insight for librarians' information literacy programs", College and Research Libraries, Vol. 79 No. 6, pp. 747-767.

Mirza, N. and Staples, E. (2010), "Webcam as a new invigilation method: students' comfort and potential for cheating", Journal of Nursing Education, Vol. 49 No. 2, pp. 116-119.

Mohamed, M.E., Mohy, N., and Salah. S., (2018), "Perceptions of undergraduate pharmacy students on plagiarism in three major public universities in Egypt", Accountability in Research: Policies and Quality Assurance, Vol. 25 No. 2, pp. 109-124.

Nazir, M.S., and Aslam, M.S. (2010), "Academic dishonesty and perceptions of Pakistani students", International Journal of Educational Management, Vol. 24 No. 7, pp. 655668. https://doi.org/10.1108/09513541011080020

O'Donnell, R., Maloney, K., Masters, K., \& Liu, D. (2020), "Library-faculty referencing and plagiarism pilot using technology-mediated feedback for change", Journal of the Australian Library and Information Association, pp. 1-17. DOI: 10.1080/24750158.2020.1813406

Owunwanne, D., Rustagi, N., and Dada, R. (2010), "Students perceptions of cheating and plagiarism in higher institutions", Journal of College Teaching \& Learning, Vol. 7 No. 11, pp. 59-68.

Pàmies, M.D.M., Valverde, M., and Cross, C. (2020), "Organising research on university student plagiarism: a process approach", Assessment \& Evaluation in Higher Education, Vol. $45 \quad$ No. 3 , $301-418$. https://doi.org/10.1080/02602938.2019.1658714

Pecorari, D. and Petrić, B. (2014), "Plagiarism in second-language writing", Language Teaching, Vol. 47 No. 3, pp. 269-302.

Pennycook, A. (1996), "Borrowing others' words: text, ownership, memory, and plagiarism", TESOL Quarterly, Vol. 30 No. 2, pp. 201-230.

Postle, K. (2009), "Detecting and deterring plagiarism in social work students: implications for learning for practice", Social Work Education, Vol. 28 No. 4, pp. 351-362. 
Ramzan, M., Munir, M.A., Siddique, N., and Asif, M. (2012), "Awareness about plagiarism amongst university students in Pakistan", Higher Education, Vol. 64, pp. 73-84. https://doi.org/10.1007/s10734-011-9481-4

Rathore, F.A., Waqas, A., Zia, A.M., Mavrinac, M., and Farooq, F. (2015), "Exploring the attitudes of medical faculty members and students in Pakistan towards plagiarism: a cross-sectional survey", PeerJ - The Journal of Life and Environmental Sciences, Vol. 3, pp. 1-12. https://peerj.com/articles/1031/

Rennie, S.E. and Crosby, J.R. (2001), "Are tomorrow's doctors honest? questionnaire study exploring medical students' attitudes and reported behaviour on academic misconduct", The BMJ, Vol. 322 No. 7281, pp. 274-275.

Sekaran, U. and Bougie, R. (2019), "Research methods for business: a skill-building approach, $8^{\text {th }}$ edition", John Wily, Toronto.

Sharkey, J.R. and Culp, F.B. (2005), "Cyber plagiarism and the library: issues and solutions", The Reference Librarian, Vol. 44 No. 91-92, pp. 103-116.

Shirazi, B., Jafarey, A.M. and Moazam, F. (2010), "Plagiarism and the medical fraternity: a study of knowledge and attitudes", The Journal of the Pakistan Medical Association, Vol. 60 No. 4, pp. 269-273.

Singh, H.P. and Guram, N. (2014), "Knowledge and attitude of dental professionals of North India toward plagiarism", North American Journal of Medical Sciences, Vol. 6 Vol. 1, pp. 6-11.

Singh, N. (2017), "Level of awareness among veterinary students of GADVASU towards plagiarism: a case study", The Electronic Library, Vol. 35 No. 5, pp. 899-915.

Soroya, M. S., Hashmi, M. A., \& Soroya, S. H. (2017), "Status of academic integrity in Pakistan: an overview", in Glendinning, I., Foltýnek, T., \& Rybička, J. (Eds.), Plagiarism Across Europe and Beyond 2017: Conference Proceedings, May 24-26, 2017, Mendel University, Brno, Chech Republic., pp. 254-262.

Strittmater, C., \& Bratton, V. K. (2016), Teaching plagiarism prevention to college students: An ethics-based approach, Rowman \& Littlefield, Lanham, MD.

Tran, U.T., Huynh, T. and Nguyen, H.T.T. (2018), "Academic integrity in higher education: the case of plagiarism of graduation reports by undergraduate seniors in Vietnam", Journal of Academic Ethics, Vol. 16 No. 1, pp. 61-69. 
Ullah, M. and Ameen, K. (2014), "Current status of information literacy instruction practices in medical libraries of Pakistan", Journal of the Medical Library Association, Vol. 102 No. 4, pp. 281-287. https://doi.org/10.3163/1536-5050.102.4.009

Vinod, K.R., Sandhya, S., Kumar, S.D., Harani, A., Banji, D. and Banji, O.J.F. (2011), "Plagiarism-history, detection and prevention", Hygeia: Journal for Drugs and Medicines, Vol. 3 No. 1, pp. 1-4.

\section{Appendix}

Survey instrument

\begin{tabular}{|c|c|c|c|c|}
\hline Strongly Disagree & Disagree & Neutral & Agree & Strongly Agree \\
\hline SDA & DA & $\mathrm{N}$ & $\mathrm{A}$ & SA \\
\hline
\end{tabular}

Section 1: Demographic characteristics

1. Gender

2. Attachment to the hospital

3. Age

4. Categories of speciality

Section 2. residents' awareness about Plagiarism

1. understand the meaning of plagiarism

2. no plagiarism is mandatory for residents

3. recognize plagiarism is wrong 

4. know to write sources of cited data
5. understand plagiarism is punishable
6. properly citing is vital for plagiarism deterrence
7. plagiarism is intellectual dishonesty
8. plagiarism is harmful in terms of quality of research

Section 3: Residents' definition of plagiarism

1. copying as a whole or parts without citing sources

2. using online or printed data without proper citation

3. paraphrasing without crediting the original authors

4. using others' works as own

5. knowingly use of data without citation

6. mistakenly information usage without quotation

7. intentional or unintentional use of published or unpublished works or ideas, as own

Section 4: Residents' knowledge of plagiarism policies and consequences

1. regarding plagiarism, CPSP has strict policies

2. know about the percentage of plagiarism acceptable to CPSP

3. know that plagiarism results in rejection of research work

4. attended workshops on anti-plagiarism policies

5. attended workshops on citation styles and management software

6. departments arrange workshops on plagiarism deterrence policies

7. supervisor inform about changes in plagiarism deterrence policies

8. CPSP uses Turnitin for checking of plagiarism

9. the supervisor is conscious about plagiarism

Section 5: Effectiveness of the IL programs towards the deterrence of plagiarism

1. Librarians are responsible to teach information literacy skills

2. Librarians provide instructions on prevention of plagiarism

3. Librarians guide you in the accurate use of citation styles

4. Librarians instruct you about citation software

5. Librarians explain the importance of citing sources

6. Librarians help in the use of digital resources

7. Librarians organize training on the writing of proposal and dissertation

8. Librarians collaborate with your supervisor to deter plagiarism

9. Librarians organize writing skills workshop for the doctors

10. Librarian inform your supervisor about anti-plagiarism policies 